\title{
Expert Systems and the Emergence of Teledesign
}

\author{
Anthony Crabbe, Dept of Design, Nottingham Trent University. \\ anthony.crabbe@ntu.ac.uk
}

Preprint of article published in Design Studies 25(4): 415-423

\begin{abstract}
This paper considers the extent to which the amateur use of expert systems for home design challenges traditional views of the design process. The issues are examined in the context of competing definitions of design. The emergence of a design process characterised as "teledesign" is then considered, wherein retailers provide a CAD/CAM service to consumers, allowing the latter to use expert systems to modify template designs and get products fabricated to their own specifications. Such a system may be seen to empower consumers as designers, rather than just selectors of products and would differ considerably from established paradigms of design, manufacture and consumption, such as that given by Baudrillard.
\end{abstract}

\section{Keywords:}

Expert systems, design theory, architectural design, design process, design models.

\section{Introduction}

An "expert system" is a computer program which performs many functions normally done by human experts. Expert systems generally comprise of an interface between the user and a knowledge system that is built out of the experiences of expert practitioners in the given field. Generally, the interface comprises the communication hardware and software needed to enable the user to interact with the computer, and it may also include other peripherals such as sensing or manufacturing equipment. The knowledge system comprises of two main parts. The first is the "knowledge base", which stores expert human knowledge on a subject in a formal and hierarchical way, containing definitions like "A = list 7", and rule-based statements, such as "if A and B, then C, not D". The second part is the "inference engine", a program which determines the consequences of a user action or command by handling each rather like a query, searching for the closest match between requested actions and pre-set rules. By such means (usually invisible to the user), the engine finds and applies the closest "expert" solution for each user action. The characteristics of expert systems may be observed in recent word processor applications, where the program goes even further than performing the "craft" role of the typesetter and plays a "professional" role in for instance, editing the grammar of the author's original text input. 
Other examples of expert systems are medical diagnosis programs and drafting of legal contracts. In design software, professional expertise is often incorporated within a straightforward drafting application, such as 3D Studio, which allows the mechanical behaviour of the model structure to be analysed by application of engineering formulae, that provide a simulation known as "finite element analysis". The use of such computer applications is now pervasive in the professional design world, and the expertise is often disguised, being embedded as just another program function, or a command on the menu bar.

The development of new expert design applications raises three major issues concerning the future nature of the design profession. The first concerns the extent to which expert systems are evolving either as assistants or as competitors to the professional. The second issue concerns the extent to which use of expert systems may alter notions of what the design process involves. The third concerns the ways in which the retailer may come to exploit the potential of expert systems as a customer service. These issues will now be examined by general reference to the medical and design professions and by specific reference to design of the home.

\section{Expert systems in medicine}

Medicine is a profession where expert systems are developing vigorously. Whole teams of doctors are developing expert databases for their own consulting areas, others are aimed at a much broader healthcare market, providing doctors, auxiliaries and even patients with such things as a preliminary diagnosis. 5GL Doctor is an example of the latter, being aimed at markets in the developing world, where access to a doctor may be difficult (see Figure 1). Accordingly, the system may be consulted at differing levels of expertise. At present, the advised role of the expert system in medicine is that of an assistant in practice management, finding data and second opinion. The main reservation within the profession seems to concern misuse of the assistant, for instance allowing it to make decisions in place of the professionals who properly carry the responsibility and indemnification. 


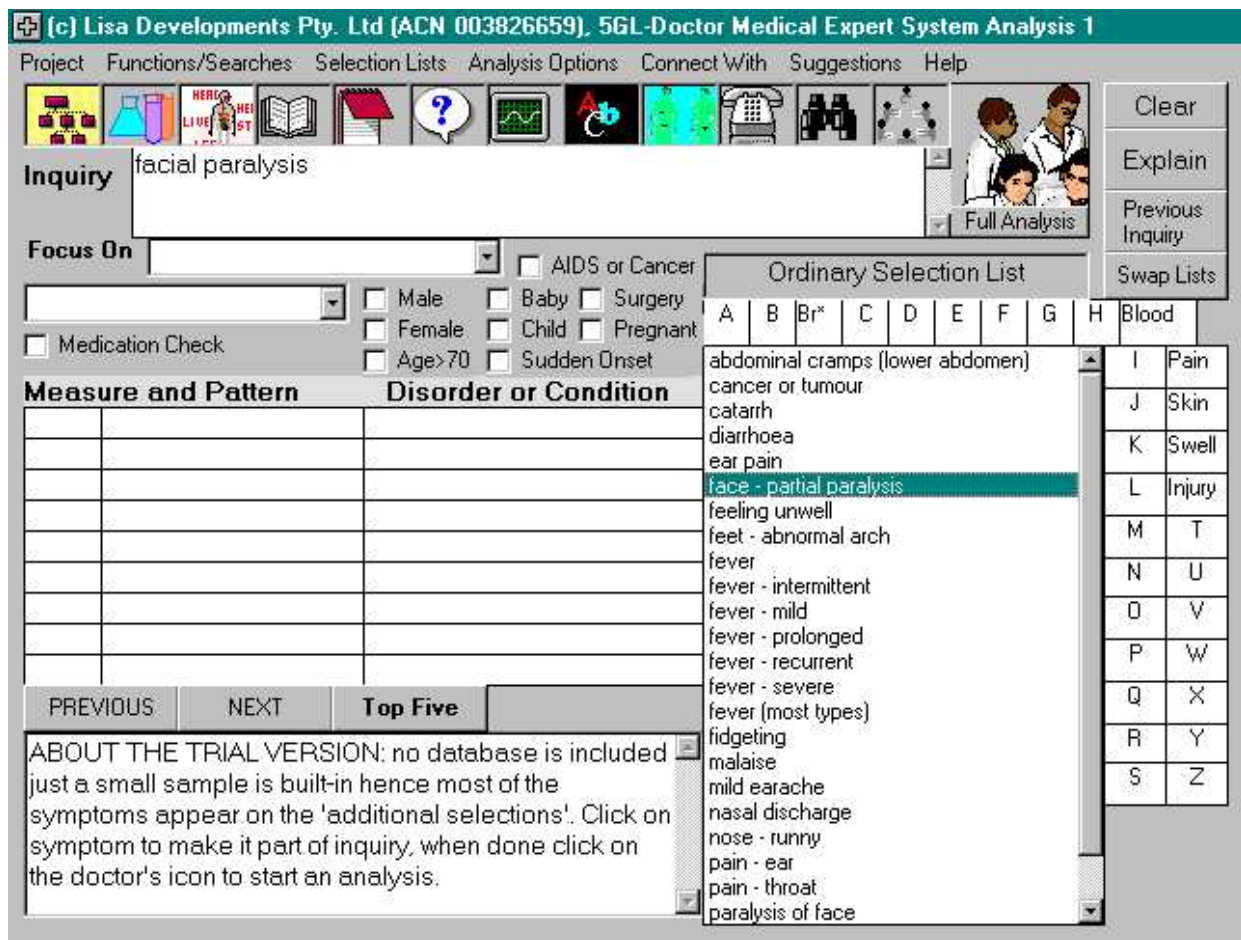

Figure 1

There appear to be mixed feelings about the future effect of expert medical systems, particularly in light of their effect on the current roles played by professionals.' The expert application can draw on a potentially limitless databank of case history and unlike the doctor, can give an immediate quantitative calculation of the probability that its diagnosis is accurate. With the right peripherals, the application might allow someone with lesser qualifications to conduct many examinations. In time, such developments could limit the general practitioner's role much more to surgical procedures, or to matters of strategy, such as practice management. To the optimists, this would represent only a change in role due to technological innovation, to the pessimists, a threat to job status and tenure.

\section{$\underline{\text { 3. Expert systems and design practices }}$}

Expert systems are also beginning to affect the role played by professional designers. Computer technology encourages many more businesses to design and print their own materials, web pages, CDs and so forth. The graphic basis of design activity makes it particularly suitable for the functioning of home computers and thus ripe for further market penetration by the software industry. Following the boom in the home Do-ItYourself market, there are now many cheap DIY programs offering the general public the opportunity to design much of their home environment from interiors and gardens to the house itself. Furthermore, influential retailers like Homebase, are actively encouraging this trend by creating their own software and catalogues of digital images that allow the customer to review products in a simulation of their own home and make their own 
design choices.

As witnessed by the popularity of the suffix "Pro" on many of these software applications, the marketing message being sent to home computer users is that computer technology will empower them to rapidly assume the creative role of professionals, in fields from which the untrained and unequipped would normally be excluded. Yet, these same applications are also used by professionals and could be seen to enhance their existing advantages over amateurs. So it is not easy to judge whether this computer empowerment is set to take work away from design professionals (as word processing did from printers), democratise the activity of designing (in an arts \& crafts kind of sense), or merely maintain the creative gap between the professional and the DIY enthusiast.

These questions oblige us to consider further the kinds of functions performed by those called "professional" designers, before examining how far they may be taken over by non-professionals. To characterise, even summarily, the activities undertaken by professional designers, is much harder than it would be for law or medicine. The design profession embraces a wide range of specialists, from those requiring chartered and indemnified status such as architects and engineers, to those who may simply designate themselves "designers", such as fashion and interior designers. Even well into the "Designer '80's" the terms "commercial" and "applied" art were generally used to describe what most today would call design. Looking at design education in Britain, as recently as the 1970's, the study of design history was just a branch of art history. The teaching of design in higher education embraces a number of differing approaches, ranging from the arts and crafts like approach of the traditional art college, to the engineering and management emphasis of the traditional university. As reviewed by John Walker, recent commentators have sought to define design in conflicting ways, some in terms of arts and crafts tradition, some in terms of a common activity pertaining to manufacturing industries and yet others in terms of a generalised problem solving activity, not even restricted to professionals.

To these views should also be added an even more pervasive one, that design amounts to a process of "valorising" utilitarian objects (in the sense of "adding" some hitherto unrecognised value to them). British versions of this idea of valorisation are to be found in ideologies as opposite as those found in the Arts and Crafts movement of the $19^{\text {th }}$ Century and the Thatcher government of the 1980's. At face value, the Thatcher government view appeared to be that design status (most obviously evidenced in "designer label" goods) added to the price that could be asked for them, and hence the profit gained from them. However, Thatcherites also seemed to have seen value addition as another instrument to be used in their bid to create a "market culture", where tensions between business and citizenry could be reconciled through a shared value system of consumer expectations and rights. In linking the role of design to social well being, Thatcherism continued to follow the precedents set by the more left-wing approach of the 
Arts and Crafts movement.

This influential international movement chose to valorise craft products by reference to the self-actualisation and personal fulfillment attained by those following craft processes. Such attainments were seen by the likes of William Morris to provide the bases for developing a harmonious social system, such as that imagined in News from Nowhere, where the profit motive became the least important driver of the production process. By comparison, the contemporary Italian version of valorisation seems to lay more stress on the values added by a more wilful, individualistic form of creativity, commonly associated with the activities of the artist. Such a view clearly encourages us to regard the outcomes of design as creations, rather than discoveries and to appreciate the individual and personal qualities of designed products, rather than their objective necessity and reproducibility.

This bewildering array of perspectives suggests a fundamental dichotomy between design on the one hand as a description for a set of activities common to anyone involved in making and on the other hand, as a description for professional activities found in only certain types of commercial production. This makes it considerably harder to determine what role expert systems have to play in design, compared say to Medicine, and hence to predict what impact they may have on those practising design professionally. An instructive approach then, is to focus on just one example, the design of the home. The example is useful because it covers a multitude of products designed by professionals with very different status, ranging from the architect to the gardener. It is also useful because we have historical precedents for the homeowner taking over the functions of the professional.

\section{Expert systems for DIY design of the home}

In addition to the store software mentioned earlier, there are now a number of inexpensive home computer software applications for house and garden design. $3 D$ Dream House from Data Becker is typical. A simple command interface allows the novice to design either a new house, or simulate their existing one with a high degree of accuracy (see Figures 2-4). Expert knowledge is built into the programming so that correct parameters are automatically set for the following: plan drawing, perspective rendering, daylight simulation, wall and ceiling thickness, stair and roof geometry, window and door placement. For the interior, the consumer can specify from a wide range of colours, textures as well as a catalogue of furnishing items. Since these items are included as scaleable bitmaps, it would only be a very short step to manufacturers providing their own catalogues of such items for the consumer to try out in their simulated home. 


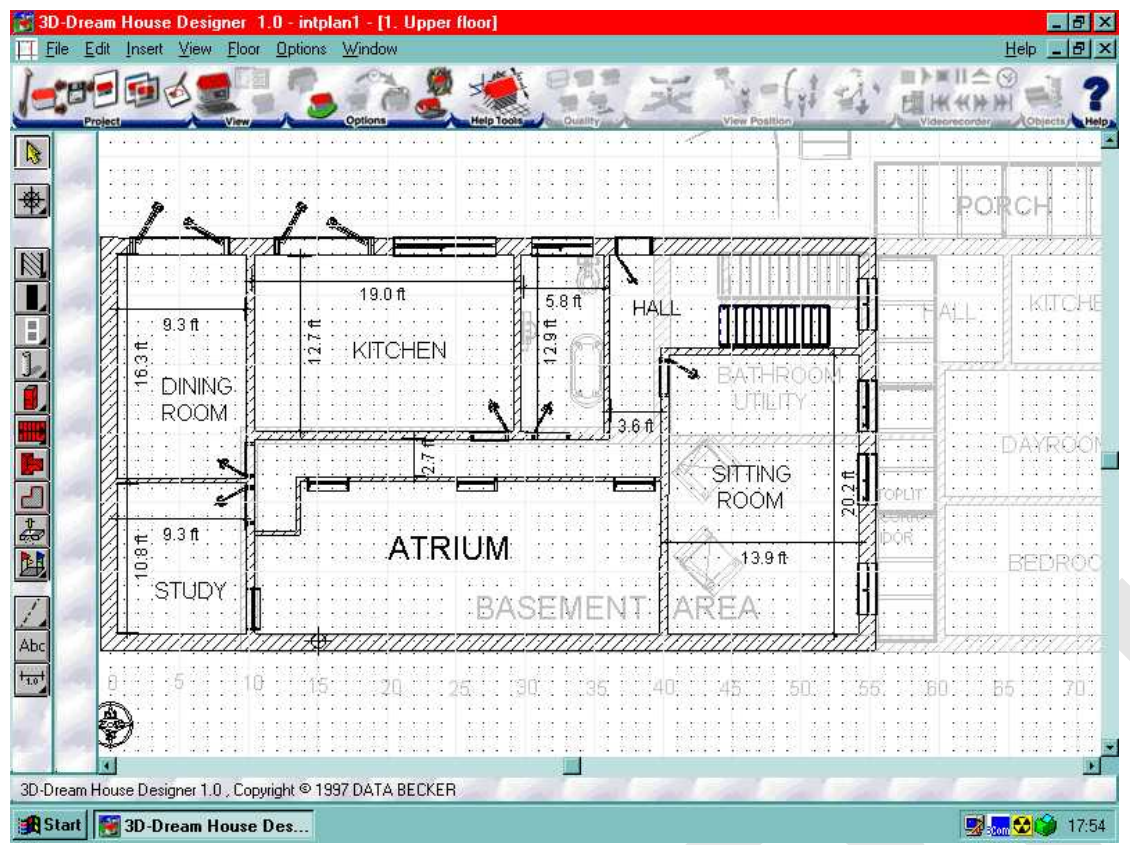

Figure 2

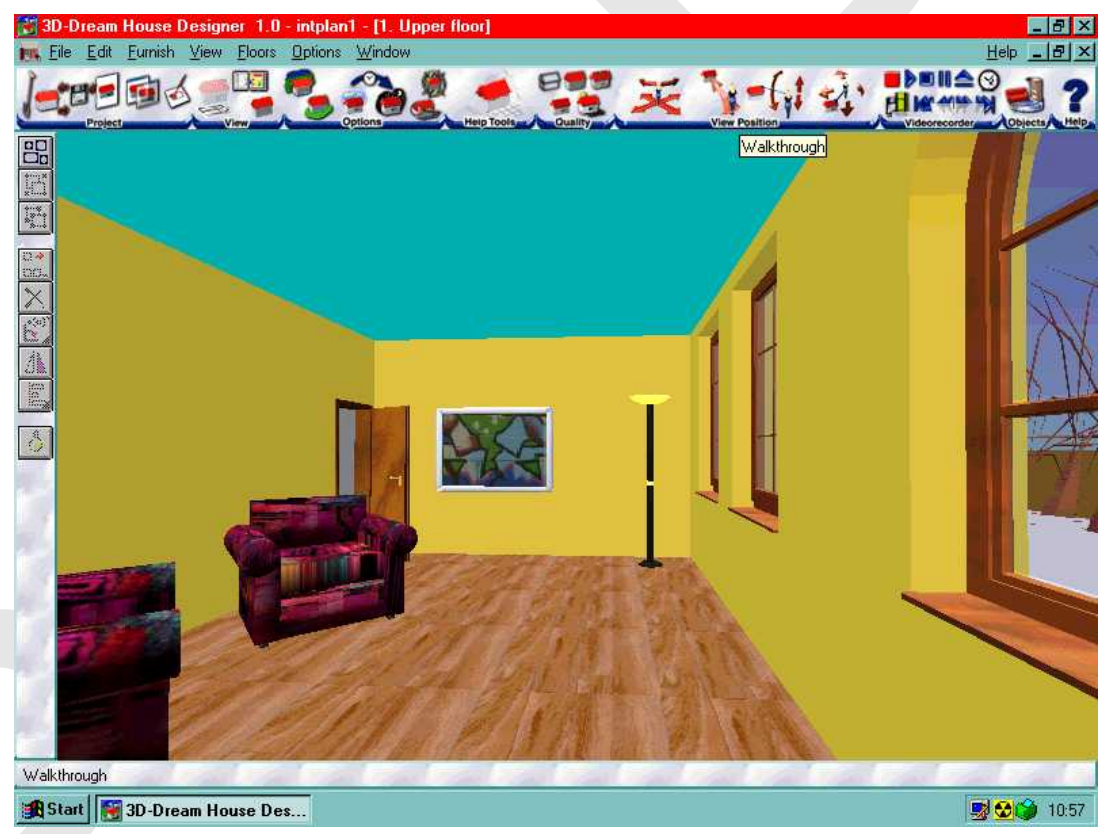

Figure 3 


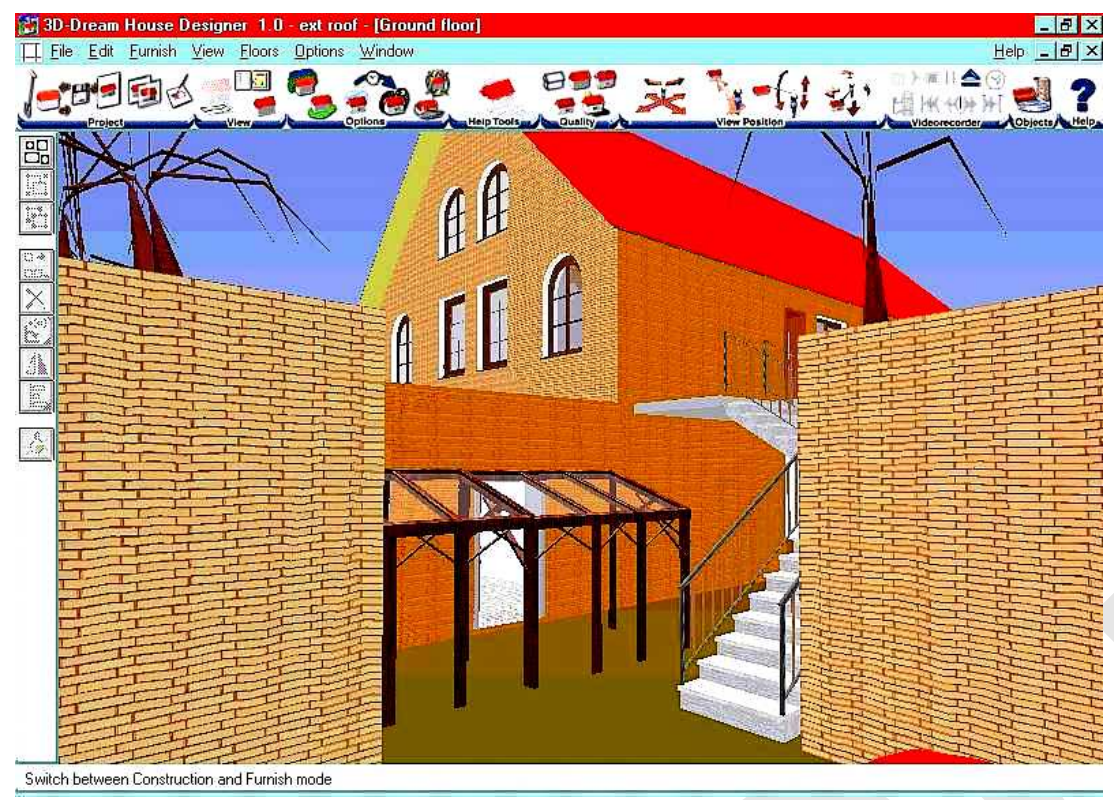

\section{Figure 4}

It would appear to be only the limitations of home computer performance and program cost that prevent inclusion of more detail such as plumbing and services, specific building regulations and materials costings. In other words, we may assume that we will shortly see expert programs which permit the homeowner to quite easily generate the complete design of a home that could be validated by regulatory authorities, without any professional input.

Architects may retort that most of the results would lack the creativity, judgement and aesthetic sensitivity, which they alone could bring to the scheme and that just as with inhouse graphics, there would be a proliferation of ill-conceived and unoriginal designs. This would be to emphasise a) the necessity of emotional and affective qualities in designing and $b$ ) the lack of such qualities in the mechanical operations of current computers. However, this view does not negate the great practical assistance dumb machinery can provide to human users. Following the example of graphic design, it is notable that applications like Photoshop allow a level of image manipulation and exploration that far exceeds the capacity of any designer to match using hand techniques. So expert systems present many, often unforeseen, possibilities for human review. In which case it could be argued that the primary difference remaining between the professional and DIY user of expert software, is the extent to which each has learnt to choose and act "well" from the solutions offered by the machine.

As the argument shifts into consideration of design merit, we see how important the definitions of design mentioned earlier become in assessing the impact of DIY design. If, for instance, we elect to define design primarily in terms of a kind of problem solving 
activity - as medical diagnosis might be chararcterised - then the only thing that really seems to separate professional from non-professional design is whether it occurs in the commercial or domestic arenas. However, doctors would be quick to affirm that proper diagnosis still depends on affects in the trained mind, like intuition and inspiration, to trigger innovative lines of enquiry, without which the science of diagnosis would never advance. This may explain the consensus in the medical profession that the expert system can never act as anything more than a passive assistant.

Such a line of argument helps demonstrate the difficulty in choosing between views of design, either as problem solving, or as a problem solving/valorising activity. Those who subscribe to the former view can always argue that problem solving is not reducible simply to a set of formulaic inputs and outputs - the creative dimension is still essential and is based in human, rather than mechanical processes. Subscribers to the latter view may argue that the problem to be solved in design is broader still: it must address cultural and aesthetic needs and so the general notion of "function" in design must encompass both the utilitarian and aesthetic. Hence, work judged as failing to address this broader notion of function could fulfill some, but not all the requirements necessary to be counted as design "proper".

These considerations make it easier to see the traditional strength of the valorising view, which helps professionals to protect their status by recourse to critical consensus. Whereas the amateur is usually designing for personal need, the professional has a vested interest in contributing through practice and commentary to the establishment of a recognisable discipline with its own rules and critical canon. Thus, the critical pitch seems very much tilted in favour of those who have established the critical canons. Yet, the significance of the non-professional contribution has often been promoted by professional champions. Historical examples are the rehabilitation of vernacular architecture by the likes of William Morris, and the artisan's aesthetic sense by Léger. The common factor linking these disparate examples is that they have come, by whatever means, to be seen as exemplars, both of products and creative processes.

The primary limitation of the valorising view lies in the extent to which it naturally tends to exclude the more engineering based kind of design, so essential to technically sophisticated and mass manufactured products. Evidence of this kind of exclusion can be found in many production processes. For instance, the blueprints of many public buildings emerge from a loop where architects periodically review and amend their conceptualisations with consulting engineers. However, as the celebrity of architects like Norman Foster and Richard Rogers testifies, the credit for the cultural and aesthetic values of the final buildings is usually attributed to the creative/artistic vision of one outstanding architect, however much that individual may point to the effort of a multidisciplinary team. 
A most striking feature of current expert systems for design is that they provide no form of guidance on aesthetic principles, such as proportion, composition and colour. Unlike their historical antecedents, the hand and the pattern book, expert systems offer the novice no advice or means of exploring the different methods of composition and construction that have achieved exemplary status. It is then hard to imagine that an expert system would ever have an effect comparable to Palladio's Four Books on Architecture, which facilitated an entire amateur architectural movement amongst the landed classes of Britain and the United States in the $18^{\text {th }}$ Century. In these books, the practical guidance about architectural elements presupposes that, for instance, the "proper" dimensions are those which have classic beauty as well as constructional or utilitarian function. Such an outlook remains embedded in the heart of modernist architectural practice, as in Le Corbusier's handbook for proportioning, The Modulor.

Since theories of proportion can be presented by means of mathematical argument, it would not be hard to imagine the incorporation of a system like Modulor into a computer application like 3D Dream Home. On the other hand the justification for choosing the given mathematical method is clearly less objective. We have only to look at the present day schisms in the architectural profession between so-called "late" and "post" modernists to see how the incorporation of utilities like a proportioning system into the software would draw the DIY user even further into concerns that hitherto, had been largely professional. Palladianism seems to have emerged as a tendency exactly because the handbook Four Books on Architecture gave a wider audience access to design theory, especially the more intellectually able amateurs, who like Lord Burlington, might otherwise have continued to focus on their other interests, such as music. By comparison, current expert design systems seem utilitarian and much less useful as educational assistants, both because their knowledge base excludes cultural forms, and because they share the generic limitation, noted by some educationalists, of hiding their program arguments from the user, in the interests of functionality.

Some architectural academics seek to overcome such limitations by exploiting the programs' abilities to generate entire catalogues of possible solutions for the geometric relationships found in differing architectural types. By such means they hope to discover the "shape grammars" of architectural types like the Palladian Villa, from which they believe they could deduce rules which would rapidly lead the user to better design solutions. But the degree to which the "better" geometric solutions would be better architectural ones, is open to serious objections. As noted earlier, design problems usually require the designer to address the users' cultural expectations, to some extent. So the assessment criteria for design success may be qualitative as well as quantitative. Public hostility in 1980's Britain to the 1960's high-rise dwelling type showed that however successful this type was in providing structural solutions for housing that were more cost and space efficient, the solutions were still examples of unsuccessful architecture, with many being demolished inside a fraction of their structural lifespan. It then remains to be seen what impact shape grammars will have on the expert systems 
used by professional and amateur architects.

The relative advantage of handbooks over expert systems is that they are created by experts whose interests reach beyond the performance of their own immediate tasks and out to the practice of others. This indicates a desire to lead the discipline, not just follow it. It is unlikely the same is true of authors of expert design systems, since they are in the main, anonymous consultants operating within a computer programming team. Seen from a market perspective, expert design systems look like another instance of the computer software industry trying to take market share off an established profession, by leading consumer demand away from professional decision making to the computer dependent kind.

The professional architect may then feel that expert systems offer little threat and are unlikely to enable the amateur to produce work of comparable standard, any more than Four Books on Architecture enabled Burleigh's Chiswick House to rival the success of it's inspiration, Palladio's Villa Rotonda. On the other hand, unlike handbooks, expert systems give their users the technical skills to rapidly generate schemes and make their own discoveries, free of the kind of prescription or burden of respect imposed by the handbook. It is to be hoped that this new functionality will, as in the shape grammar project, lead to new creative insights amongst practitioners of all kinds. It is to be feared that culturally empty expert systems will give the DIY enthusiast a limited understanding and false sense of confidence, which will lead to a proliferation of uninspiring design jobs.

\section{Teledesign}

If only a minority of consumers have the time and inclination to use expert systems in place of professionals, expert systems still offer one more challenge to the professional designer, especially in the field of home furnishing. This is a more significant challenge since it involves both the marketing behaviour of suppliers and the shopping habits of the consumer. Tucked away in the files of $3 D$ Dream Home is a folder of images labelled Ikea. This contains scaleable bitmap images of furnishings designed by that company. It is then easy to envisage the following scenario.

There are shops and DIY stores that already offer a service whereby the shopper can provide details of say, their kitchen, to a sales assistant who can then use an easy to learn application, similar to 3D Dream Home, to make a virtual model of the kitchen. Guided by the shopper's preferences, the assistant can drop in the images of various product ranges of kitchen fittings and indeed cost each ensemble to the customer's satisfaction. The purchase of the final choice can then be fed into the supplier's order system, which may in turn be linked to the manufacturer's stock and production systems, giving both companies the benefit of "just in time" manufacture and sale. There are also after sales 
benefits for manufacturer and retailer, in cases where the purchase is made electronically, rather than with cash. The companies can use the purchase transaction data to profile both their customers and each other in order to target their future marketing, exactly as is done in other stores, such as supermarkets.

Going one step further, it is notable that the computer generated images of products can be easily re-dimensioned, re-coloured, indeed re-formulated, as can any images in a computer application. If the manufacturer constructs the images in a computer application that relates to his/her own design software, then these images, far from being bitmaps, could be the designs themselves that the customer modifies. Since the designer's original software can have inbuilt expert functions, such as finite element analysis and costing, the customer's modifications can be automatically appraised and relevant production parameters set. Because the design files can be generators for a CAD/CAM manufacturing system, the opportunity exists in the case of many home design products, for the customer's final choice to be sent directly to the manufacturing line for fabrication as a bespoke item. Such a process could be characterised as "teledesign", a process where the consumer uses communications technology to execute the final design, remote from the design studio (represented in Figure 5). Indeed, technology for clothing design and manufacture is fast moving towards this point, with companies like Assyst and Lectra offering store-based or online software that allows customers to enter both their measurements and preferences into existing garment design templates. The customer may even design their own textile prints and the selected fabrics can then be marked and cut ready for sewing.
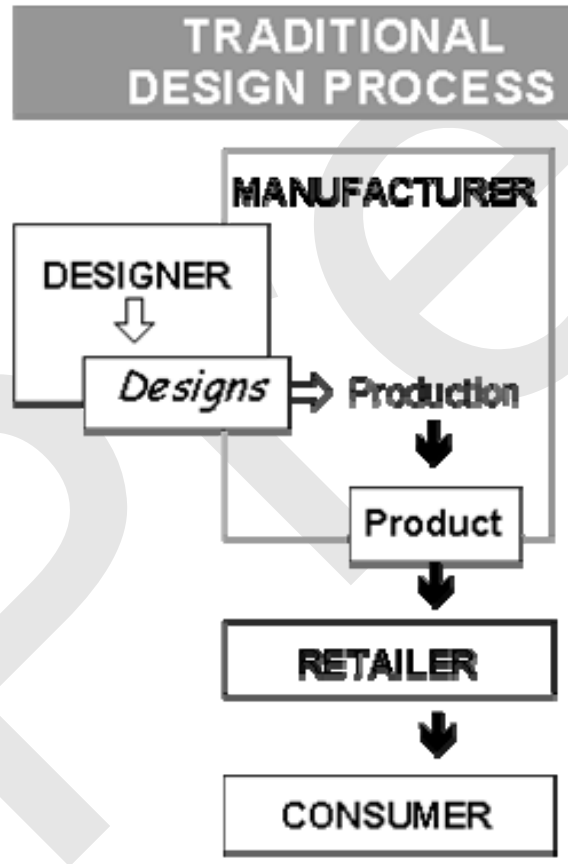

TELEDESIGN

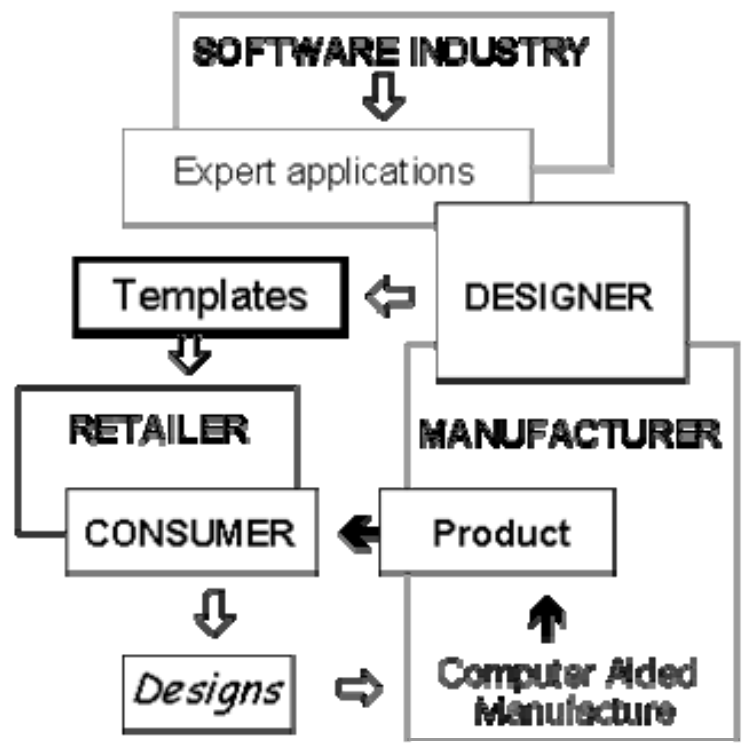

Figure 5 
In this respect, expert systems seem set to have an even more profound impact upon the design profession than on medicine or law. Firstly, many designers may find themselves more engaged in the design of templates, analogous to those already found in presentation software like Powerpoint, where users may take a pre-designed graphic slide and from that adjust every element to their own needs. The final product is then created to the user's design, following the designer's earlier cues and hints - a system quite unlike Baudrillard's famous characterisation of products as serial reproductions of the designers originating model. This suggests secondly, that teledesign may make the professional designer more contingent and less integral to the manufacturer's needs.

Thirdly, it suggests that the designer's solutions will be less sacrosanct, the designer will be less of an arbiter of what is available to customers and more a facilitator of customer choice. Since few design specialisms involve indemnification, the consumer would be free to ignore professional advice in a way less likely found in medicine or law. Pictured in evolutionary terms, it would take a very strong initial design by a professional to survive without mutating into quite different forms driven by consumers' desires.

Such a production system could also lead to a different kind of valorisation of products, where the purchase of durable goods would no longer be just a matter of selection, but one of creation. There might even be parallels with the vision of News from Nowhere, where a technology (ironically, an industrial one) creates a production system that gives ordinary folk the power to create their own material and cultural environment, manifested in a sociable plurality of individual creations. However, this is only presuming as did Morris, that the creative impulse is common to most people, that they do not want to delegate creative responsibility to others (especially status figures) and thereby valorise their goods by association with a cultural milieu other than their own. Consider that Morris himself, the son of a Victorian brewery owner, aspired in thought and deed to the world views of both medieval knights and artisans.

Yet, if e-commerce realises even part of its much vaunted potential, then it can be seen that expert systems would be essential tools, and teledesign even more prevalent. For instance, the consumer might store on his/her home computer, a virtual model of his home, created by expert software. This model would be linked to retailers' catalogues, so that the consumer can review new items in situ, then customise and order his chosen design, all at his home computer. In such a future, do not be surprised to receive an unsolicited e-mail that reads

"Valued Customer, our records show it is three years since you last re-furbished your kitchen. As you will see from the attached video file, our leading designers here at Ikeo have re-fitted your kitchen, using our latest Smørsgabord range, enhanced by a range of new paint finishes from..." 
On the other hand, don't be surprised to discover that it was an expert system which automatically loaded the new product ranges into the kitchen design file and the customer who took credit for the re-design.

\section{REFERENCES}

1. Romiszoski, A. Artificial intelligence and expert systems in education: progress, promise and problems. Australian journal of Educational Technology, 3(1), 6-24 (1987).

2. Hillson SD. Connelly DP. Liu Y. The effects of computer-assisted electrocardiographic interpretation on physicians' diagnostic decisions. Medical Decision Making. 15(2):107-12 (1995, Apr-Jun).

3. Gardner RM. Lundsgaarde HP. Evaluation of user acceptance of a clinical expert system. Journal of the American Medical Informatics Association. 1(6):428-38 (1994, Nov-Dec).

4. Ridderikhoff J. van Herk E. A diagnostic support system in general practice: is it feasible? International Journal of Medical Informatics. 45(3):133-43 (1997, Jul).

5. Lovell NH. Celler BG. Implementation of a clinical workstation for general practice. Medinfo. 8 Pt 1:777 (1995).

6. Walker, JA. Design history and the history of design, pp28-32, Pluto Press, London (1990)

7. Jervis, S. The Penguin dictionary of design and designers, Introduction, Penguin, London (1984)

8. Bayley, S. In good shape: Style in Industrial Products 1900-60, Design Council, London (1979)

9. Papanek, V. Design for the real world: human ecology and social change. 2nd ed., Thames and Hudson (1985)

10. Pearman, H. Cautious optimism at Number Ten, Design , London, (March 1987) p459.

11. Morris, W. News from Nowhere and other writings, (1891), ed. Wilmer C. Penguin Books, London (1993)

12. Branzi, A. We are the primitives (1985), in Design Discourse: History, Theory, Criticisim. Ed. Margolin, V. University of Chicago Press, Chicago (1989).

13. Radice, B. Ettore Sottsass: a critical biography. Ch 3, Thames \& Hudson, London (1993)

14. Léger, F. The machine aesthetic: The manufactured object, the artisan and the artist, 1924, reprinted in Benton T \& Benton C. Form and function, Crosby Lockwood Staples, London (1975)

15. See e.g. Pawley, M. Norman Foster: a global architecture, Thames \& Hudson, London (1999)

16. Palladio, A. The four books of architecture 1570, Trans. Ware I., Constable, London (1965)

17. Le Corbusier. The modulor. Trans de Francia P. \& Bostock A. Faber, London (1954)

18. Op cit. note 1 .

19. Stiny G, Mitchell W J, The Palladian Grammar Environment and Planning B: Planning and Design 5 5-18 (1978).

20. Madrazo L, The Concept of Type in Architecture, An Inquiry into the Nature of Architectural Form, Ph.D. Dissertation, University of Zurich, ETH Zentrum No. 11115 (1995) Epilogue.

21. http://www.assyst-intl.com and http://www.lectra.com

22. Baudrillard, J. The system of objects (1968), reprinted in Design after modernism: beyond the object ed. Thackera J. Thames and Hudson, London (1988) 